(c) EUSP, 2016 |e $\mid$ ISSN 2310-3817 $\quad$ Vol.4 $\quad$ SLCS

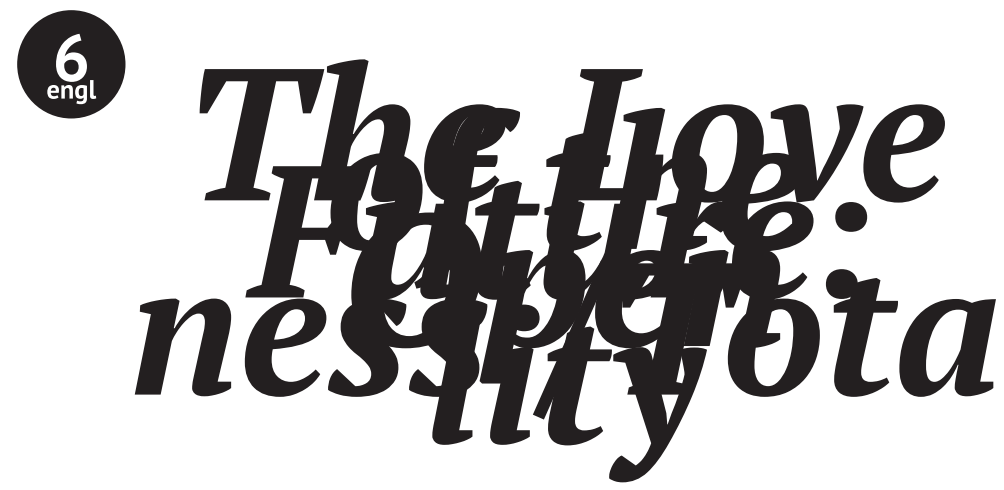

\title{
The Love of the Future: Openness/Totality
}

[At the Poryadok Slov bookshop, 2 April, 2015] Artemy Magun, Oxana Timofeeva, Yoel Regev, Galina Rymbu, Yelena Kostyleva, and others

\section{Introduction \\ Multiple-love: Polyamory and its Discourse}

Yelena Kostyleva

Emerging in 1990s America among the educated white middle class, polyamory is not so much a trend or a movement, not so much a practice or theory, as a new ethic of human relationships that has long found no place within the framework of the nuclear family and cannot be described within its terminology. That which is commonly referred to as the crisis of the traditional family is, in essence, the emergence of new forms of the same, but until the appearance of the term "polyamory" these forms had no language to describe themselves except in negative terms with regard to traditional social mores.

In its doctrine, polyamory has brought together the most recent popular achievements of European humanitarian thought, including gender theory, feminism, and queer theory. In principle, it represents a kind of collection and complex of explanations of why it is that entering into intimate relations with multiple people can be just as acceptable from the 
point of view of the wider society as doing so with a single partner, and of how this can be done in an ethical manner without adversely affecting, oppressing, or causing suffering to anyone (utopian components are, of course, just as present in polyamory as the sadomasochistic).

Non-repressive polyamorous relations, ethical non-monogamy, conscious and responsible non-monogamy, consensual non-monogamy, or simple polyamory are distinguished by several principles that are absent in other forms of polygamy. These are the voluntary aspect (of consent, in distinction to polygyny), honesty (the awareness of all participants as to the structure of the relationships in which they find themselves; by which polyamory can be distinguished from adultery), responsibility (marking it out from swinging or any other forms of purely sexual relationship), trust, and the overcoming of jealousy (through which two points polyamory approximates a Christian or altruistic values system). To these, the principle of non-hierarchy is often added, though there exist variations of polyamorous relationships whose participants recognise hierarchies as a structuring principle that are complex in comparison with those of dyadic unions. In the formation of a new system of ethics for love relationships that is taking place before our very eyes, a great role is played by criticism of the elements of patriarchy found within them, as well as by the analysis of power relations.

Polyamorous unions, numbering in the United States at around half a million, are classified according to their degree of openness, periodically merging to indistinguishability from group marriages or open (but at base traditional) "Swedish families," and so on.

In line with the massive changes in love practices and the reinterpretation of the very concept of love that are taking place, radical questions raise themselves. If the very event of intimacy no longer involves either biographical consequences (pregnancy or disease) or even social condemnation (rather the opposite), then what exactly are sexual relationships today? For polyamorists, they definitely exist, but what is their status? To put it another way-what is it now, outside the framework of traditional bourgeois (prohibitive) morality, that is signified by the phrase "my sexual partner"? Who is this person? What links them with me? And is not the subject of polyamory the relationship itself, rather than the people who comprise it, or the ideology by which it is accompanied?

Engels, in The Origin of the Family, Private Property, and the State, anticipated just such a turn of events:

Full freedom of marriage can therefore only be generally established when the abolition of capitalist production and of the property relations created by it has removed all the accompanying economic considerations which still exert such a powerful influence on the choice of a marriage partner. For then there is no other motive left except mutual inclination" (Engels 1993: 50). 


\section{Discussion}

The first attempts to organise the "new family" are already taking place under capitalism, however. These attempts are aimed towards a change in the forms of distribution of libido and the libidinous economy. In the polyamorous nucleus, elements of the bourgeois family have been preserved-the general opinion being that polyamorists are not revolutionaries, but people in slippers, though there is some revolutionary potential in them. Falling into the gap between the unforbidden and the unpermitted and remaining invisible to regulatory structures, they, unlike the LGBT community, have no desire to be recognized by the official authorities or the church. Polyamory has another mechanism for legitimation. It affirms itself with the help of extensive scientific and media discourse-beginning, arguably, with the most popular book on polyamory, The Ethical Slut by Dossie Easton and Janet Hardy (2009), and the classic works by Deborah Anapol, The New Love Without Limits (1997), and Elisabeth Sheff, The Polyamorists Next Door (2014). More in-depth investigations can be found in the polyamory library at the Kinsey Institute, ${ }^{1}$ where various aspects of the phenomenon are examined in the framework of psychology, sociology, philosophy, and gender, queer, cultural and interdisciplinary studies. The interdisciplinary approach is also adopted by the international conference on the future of monogamy and nonmonogamy, which has taken place four years in a row at the University of California in Berkeley. ${ }^{2}$ And, of course, polyamory seeks its basis in artistic traditions-and fortunately, the history of free relations has been recorded in art for as long as they have existed.

The very flexibility of structure in the polyamorous family compels it to be constantly conceptualizing and reconceptualizing itself. Life in the polyamorous nucleus of society is a constant doubting of the universality of universal laws on how to live and the constant establishment of them for yourself: each time-anew, and each time-from scratch.

\section{Bibliography}

Anapol, Deborah M. (1997). Polyamory: The New Love Without Limits: Secrets of Sustainable Intimate Relationships. San Rafael, CA: Intinet Resource Center.

Easton, Dossie, and Janet W. Hardy (2009). The Ethical Slut: A Practical Guide to Polyamory, Open Relationships \& Other Adventures, $2^{\text {nd }}$ ed. Berkley, CA: Celestial Arts.

Engels, Friedrich (1993). The Origin of the Family, Private Property, and the State. https:// www.marxists.org/archive/marx/works/download/pdf/origin_family.pdf.

http://www.kinseyinstitute.org/library/Pdf/Polyamory\%20Bibliography.pdf.

International Conference on the Future of Monogamy and Nonmonogamy. http://www.thesaar.com. 
Sheff, Elisabeth (2014). The Polyamorists Next Door: Inside Multiple-Partner Relationships and Families. Lanham, MD: Rowman \& Littlefield.

The Kinsey Institute for Research in Sex, Gender, and Reproduction Library. Polyamory Bibliography. Last modified December 2008. www.kinseyinstitute.org/library/Pdf/ Polyamory\%20Bibliography.pdf.

\section{Discussion}

Konstantin Shavlovsky: Good evening! The initiative to organize our meeting today first came about in connection with an exhibition that took place in Saint Petersburg under the title "And What About Love?" and the address given by Yelena Kostyleva at that exhibition on the theme of polyamory. After this exhibition and speech, heated discussions broke out on social networks, and the suggestion was soon made to take this out of the virtual environment and make it public and open, and to hold it here, in Poryadok Slov-for the selection of this venue I thank our participants. I shall now introduce the main participants of the discussion. We hope that all our audience will join in, as the topic under discussion is one close to the heart of everyone present-of which I have no doubt. And so, the discussion title is "The Love of the Future: Openness/Totality." Its participants are: the philosophers Artemy Magun, Yoel Regev, and Oxana Timofeeva, and the poets Galina Rymbu and Yelena Kostyleva.

Yelena Kostyleva: In this discussion we are definitely not going to get into any general FAQ about polyamory. Suffice to say that this new trend is widely discussed in the English-speaking world and that is mainly where it takes place. Polyamory has had a vast ideology "bolted on" to it. Discussion revolves primarily around such aspects of polyamory as its openness, inclusivity, honesty, and various other ethical principles. The movement is of interest insofar as it has tried to work out, within itself and by itself, a certain new ethics of relations, by force of the ethics of traditional relationships not describing the present subject as ethical relationships in principle. It is supposed that if people live together in a couple and then marry, then everything which occurs beyond the bounds of this marriage is instantly a betrayal and various other bad words. Many do not wish to define themselves by means of various bad and offensive words, but would like to describe the matter in ethical categories, desirous of being an ethical subject. It seems to me that something is happening with this most amoral subject that originated with Nietzsche following the "death of God." This amoral subject, I believe, no longer wants to be referred to as amoral, and does not wish to define itself according to traditional morality at all.

I would like to go further in sharing some thoughts on how it is that I now picture this polyamory to myself. And it is precisely as an attempt 


\section{Discussion}

to return to the language of paradise in the situation of the confounding [of languages] at Babel. Crudely speaking, there once were two people, and they understood one another fairly well, and we suppose they had some kind of paradise language in which they spoke. Subsequently, they were cast out, and then came the Flood. And then, after the Flood, the descendants of Noah decided to build this Tower of Babel, to set up a kind of human phallus - this tower, which was pointed towards God.

As a couple, it's hard to come to an agreement, even by yourself it's hard, but it's far harder to agree when there is a certain number of people. And yet even so, when we postulate this attempt to speak in the tongue of paradise in a small group, what is it that we get then? We come up against the difficulty of translation from all languages in to all the others; we get a certain sort of life in the absence of power, in the absence of the tower, in the absence of God.

I will stop there for the moment. Perhaps somebody else would like to continue.

Artemy Magun: It seems to me that Oxana Timofeeva came out at a certain point on the social networks as an antagonist against this concept, though on first impression she seemed rather the contrary. There was nothing of paradise in what she said, but on the other hand there was the concept of polyamory as one of new collective relations. Oxana Timofeeva, as though from the heights of her understanding of love, came out categorically against this concept. I would like to hear her arguments.

Oxana Timofeeva: I cannot say that I am categorically against it, as such. I acknowledge, however, that my first reaction to the idea of polyamory as a potential positive programme really was one of resistance. Unexpectedly, even for myself, I then ended up on the extremely unpopular side of a defence of traditional institutions connected with traditional ritual practices-such as monogamous marriage, courtly love, romantic love, and so on. That is, taking into account that these institutions may fulfil certain repressive roles in society-particularly in contemporary Russian society-I found myself playing devil's advocate.

I have taken an interest in matters of love and sexuality for many years, though more theoretically than practically. And so, purely theoretically, I often pose the question: "What will love be like under communism?" This is a very important question, one that concerns the very foundations of our way of life. Suppose we are now living in a society where the fundamental antagonisms characteristic of capitalist society have been resolved-those connected with money, exploitation, alienation of labor, social injustice, and so forth. Will this mean that some kind of easy life in paradise has begun for us, lacking in any contradictions at all? I think not: if the economic contradictions imposed by capital are removed, what we then will have uncovered are the deeper, more funda- 
mental antagonisms of human existence, and we will have to understand what to do with such things as death, disease, and jealousy.

Let us suppose the existence of free love in our free society. And you have fallen in love with a certain comrade, but he doesn't love you and is in love with another comrade. Should he love you in return, and you, in return for this, love the other comrade that he is already in love with? No longer can you take refuge in the routine of unavoidable wage labor from the pain caused by the suddenly revealed emptiness of unrequited love. On the contrary, unalienated free creativity awaits you, which, possibly, may only serve to exacerbate your suffering. I have long been doubtful of the idea of liberated love and sexuality. Wilhelm Reich, in describing the Russian Revolution, lamented that no sexual emancipation followed the political revolution in the Soviet Union. And today we can point to the fact that, in Europe and America, no political revolution was forthcoming after the sexual revolution of the 1960s (thus demonstrating that the one does not necessarily suppose the other).

The varied models of liberated sexuality with which liberal-democratic society gratifies us represent the conquests of this sexual revolution. However, in my opinion, the radical emancipation of the subject is linked with the necessity of passing through the negativity of love, jealousy, and the rituals and affects connected with them. You need to learn to love at least one person before you can set about organizing relationships with many others. Furthermore, in some sense, in the society in which we live, we might not yet, perhaps, have achieved genuine sexual relations, and we are all in some sense still innocent. We have not yet been subjects of that transformative event which, like the kiss of the prince, turns the frog into the princess. The impossible horizon of communism is linked for me with such a transformative event, with a hypothetical first kiss which we have always been waiting for, and in our confused expectation of which we simply masturbate, in solitude or beside others who are as lonely as ourselves. Our relationships in the capitalist world are such that even our partners are perceived in the context of certain part-objects, organs, and economic functions. The very word "partner" is itself taken from the world of capitalism.

Artemy Magun: This to me seemed a hysterical theory of love. I can imagine what an obsessive theory of love will look like: "Why does everybody love me?! There's love everywhere! Might it not be time to move onto friendship?”

\section{Oxana Timofeeva: And why hysterical?}

Artemy Magun: Well, where to begin? In it can be heard the following cry: "There's no genuine love anywhere. Where is it? Let's go and find it!" 


\section{Discussion}

Yelena Kostyleva: I would like to add literally three words. I want to simultaneously agree and disagree. First of all, we believe in, so to say, psychoanalytical communism, where all this has already been gone through, where in the process of analysis you have already gone through all this monogamous love and learnt thereby to love another. Of course, polyamorists most often emerge "from the good life," in the sense that there exist certain phases in the building of a polyamorous identity. Among these, the monogamous phase is an absolutely vital step on the path to polyamory, as the polyamorists say. But, in actual fact, and this is why I don't have an affinity for your theory as a whole, it seems to me that you are suggesting that polyamory is connected with a certain simplification and flattening of feelings when you say "It's so difficult with one, and here you have to deal with several..." both technically complicated and with a supposed internal simplification and some kind of superficiality. I'd like to say something in relation to this.

It seems to me that polyamory does not bring an automatic simplification of feelings or relations. Again, if we continue with this line of simplification, we come to the animal. The question is, is polyamory the highest form of the family or the opposite-its most primitive form? I devoted considerable discussion to this in my address.

Artemy Magun: There was another interesting point in the initial speech, Yelena. As a counter example, the case might be brought up of the commune that was built up by the Viennese actionists around Otto Muehl in the 1960s. It's one often raised by those who oppose polyamory. The commune was large, and at first it was a success. They had organized a clear-cut and stable institution, but it all ended up in a peculiar primitive horde along Freudian lines, where Otto Muehl was the sole desirable man and had the rights to all women. As the women didn't want to have relations with the other men, they had to form a queue to have them with Otto Muehl himself, who, when he got older, began to take advantage of this and ultimately ended up in jail for paedophilia, sexual abuse, and so on.

This is a sad story, and it is cited by contemporary politically correct Europeans in this context: that, under the slogan of emancipation-of which Oxana was just speaking-we actually get the tyranny of the strong, but of the strong in a social sense, i.e., of men. And so polyamory is bad from the point of view of feminism. It is actually a pretty cunning means of oppressing women, and Otto Muehl ended up with a virtual harem by means of all this chatter about polyamory. And you can indeed look at it like this. I don’t myself, but there's another “devil's advocate” for you.

Yelena Kostyleva: Non-hierachicalism is a basic principle of polyamory... 
Artemy Magun: And it was for them too. But when you have formal non-hierarchicalism, you informally get hierarchicalism.

Yelena Kostyleva: Maybe this is more of a practical issue?

Artemy Magun: No no, it seems to me that it's absolutely a matter of principle.

Yelena Kostyleva: Then it's a matter of human nature. Let's give some thought to the theme of what exactly love is, or, for example, what the unfortunate love is that Oxana was just speaking of as such a lofty, platonic form of love. Polyamorists would have it that, without having analyzed power relations or the factor of power in relationships, it's impossible to talk about any kind of love at all.

Artemy Magun: Very well. But how do you analyze the power factor?

Yelena Kostyleva: In general, I came to the conclusion that love is also power.

Artemy Magun: Rightly so, and here I agree with you. And consequently, you cannot build an anarchic commune around love.

Yelena Kostyleva: Around love, no...

Artemy Magun: Excellent. You end up with the situation that a commune has to have a hierarchical structure...

Yoel Regev: In general, it's similar to the principle of democratic centralism.

Artemy Magun: Structurally, yes. But it's another question entirely how exactly it is structured. Would anyone like to speak who hasn't done so far?

Yoel Regev: I, perhaps, could continue with the theme of love and sex under communism, and even, perhaps, attempt to continue with some outlines of a positive program for the sex of the future-sex of which we know virtually nothing, or are only just beginning to find out.

As I see it, the concept of polyamory contains two doubtful points. On the one hand, there is not so much a simplification of feelings (insofar as I realize that it is not at all inevitable that feelings will be simplified), as a kind of absence of conflict. It appears that all conflicts are the result of some kind of prejudice, from which it is possible to rid oneself. The second point which I find doubtful is that of the moralizing prescriptive 


\section{Discussion}

aspect. It is supposed that it is enough to give a simple moral injunction to the subject: "Rid yourself of jealousy, rid yourself of prejudices!"-and if the subject is possessed of the willpower to perform what is demanded of him, then all is in order. It seems to me that analysis needs to be made not so much of the relations of power, but of the economic structure. I would like to suggest that which appears to me to be the Bolshevist approach to the problem of contemporary sexuality. That of Lenin, in particular, standing out against two extremes. On the one hand, polyamory seems an obviously anarchist project-and nobody seems to be trying to hide this. The anarchist project supposes that the apparatus of the state and power relations can simply be seized and abolished if there is sufficient willpower to do so. On the other hand, opportunists of all types, revisionists, and Mensheviks propose that we stay within the existing state apparatus and, by infiltrating it, produce certain micro-changes, which, in the long run, by the path of reform, might lead to changes in the general condition of the state.

It seems to me that, in relation to contemporary sexuality, these two polar extremes are clearly represented, by polyamory on the one hand as the anarchist project for the abolition of marriage and the institution of monogamy-and on the other by such practices as adultery-spousal infidelity, which resemble nothing other than typical Menshevism.

Artemy Magun: The struggle has been transferred onto the level of civil society.

Yoel Regev: Yes. And what in fact does Lenin have to say about these two concepts? Lenin says that both of them are founded on a failure to understand that it is not a matter of the apparatus of the state. Yes, they do relate in some way primarily to the apparatus of the state as the apparatus of coercion. But in actual fact, the apparatus of coercion is based on a certain economic reality. Having changed this economic reality, it then becomes possible to manipulate the state in some way. And it appears exactly the same to me here, in the realm of sexuality, where it is necessary, first of all, to alter a certain economic (the libidino-economic, as Yelena Kostyleva put it) situation. Or, I would say, rather, the ontological-economic situation. A certain economics of the distribution of reality, which makes itself known via both the libido and in direct socio-economic terms. It seems to me that this economy is best expressed in a scene from the film The Geographer Drank His Globe Away. This film clarifies the problem of contemporary sexuality best of all. At its center there is a hero who doesn't have sex. What's more, in Aristotelian terms, this is not an absence, but a voidness. His not having sex is not due to any general omission on his part to pursue it because he is engaged in other activities instead; he doesn't have sex precisely in those situations in which, generally speaking, he should do so, but in which he simply does not. At the 
beginning, he doesn't have sex with his wife, and then he doesn't have sex with his student. And the main scene, in which we see the key revelation of the truth of the contemporary economics of sexuality, is one in which he does have sex, but doesn't climax. And this is emphasized. When he explains why he hasn't experienced orgasm-in answer to the woman who says she feels sorry for him (for not reaching orgasm)-he expresses the truth about contemporary sex. The truth about this economy, and one that needs to be transformed. He answers her something like this: "I want to be a saint." What does it mean, "to be a saint"? [He continues]: "I want no other person to become the hostage of my happiness; that no other person become the hostage of my meaningfulness." It appears to me that this is the truth of sexual economics-and it is also that point which must be changed.

Some transformation of sexual relations is only possible under conditions whereby the entire structure of subjectivity is changed, when the subject is constantly on the lookout for something that will give him some ontological groundedness, in which the subject is faced with some unsolvable challenge which he, nevertheless, must constantly fulfil-to take on some meaningfulness and become something, even though he is actually unable to do anything, because he is lacking in any substantiality or definition.

It is impossible simply to reject something in order to lend sexuality an ontological value, because the sole path leading from this rejection is to make sex meaningless. It seems to me that this is not the right path. Insofar as sexuality is actually in some sense a decisive weapon and decisive instrument in the transformation of reality.

I would like to describe, from my point of view, what this transformation of sexuality might look like. For this, naturally, it is necessary that the entire structure of subjectivity be changed, and the entire structure of reality in general, at the center of which there stands the figure of the immanent impossible. I will not lay out all the phases of this transition now. I will say only this, that within the framework of this transition, as I see it, the perception must be made possible of both the substantial and the objectively existing continuum of what takes place with the subject. The continuum of those points through which the subject passes, of those events, those challenges, which he encounters on his life journey, in spite of the fact that they are linked with one another solely by this trajectory of his route. In order that what I have in mind be better understood, I say that this is actually quite close-not for nothing did we speak here of sainthood-to the traditional religious, Kabbalistic for example, model of man, who lives in order to raise the spark of holiness from the envelope of impurity.

Artemy Magun: This is Pasolini’s Teorema. 


\section{Discussion}

Yoel Regev: Yes, it's Pasolini's Teorema. On the other hand, it's many of Rohmer's films too. The slogan of this kind of understanding of sexuality, I would say, is the phrase uttered by the hero of the film Ma nuit chez Maud, when he says "Each girl I met posed a new moral challenge." I think the word "moral" here is superfluous. And clearly it doesn't necessarily have to be a girl, either.

\section{Yelena Kostyleva: Why is it superfluous, then?}

Yoel Regev: Because, as it seems to me, this is a contraction. It's actually a new ontological challenge. A challenge of the transformation of reality, not of man. I mean, in full seriousness, in the future communist society we will be capable of relating to sex in a similar way as in David Zindell's novel about the order of mathematician-pilots, who travel through subspace by means of combining with the computer systems of a ship; as they solve mathematical theorems, they move through space. Resolution itself is movement. And there is always the possibility of getting lost in endless dead-end branches of proof, in which they would remain forever in their space and never leave.

It seems to me that future sexuality-and I mean this quite literallywill simultaneously be a means of transforming reality, allowing us to move through reality. To move, moving reality itself, unlocking situations, transferring us into situations in which the formerly impossible is made possible. Properly speaking, this is the main postulate of the materialist dialectic. That which we can comprehend, that which we can do, are defined by the conditions of the situation in which we find ourselves. It seems to me that communist sexuality is the sexuality of unlocking situations, changing the conditions in which we find ourselves, and making possible the understanding, knowledge and action which were impossible in previous situations. Precisely because of this, each new partner is a new challenge, a new means of unlocking the situation, a new means of translocation. In Hemingway's novel For Whom the Bell Tolls, the gypsy woman, describing the sexual act between the main characters, says: "The earth moved." This is transformation. She says that such a thing happens only three times in one lifetime. But this three times is in the present-day capitalist order, while under communism I believe it should happen every time. Real communist sex is sex in which the earth moves every time. Each sexual act will lead to transformation and unlocking.

Artemy Magun: You, Yoel, are a highly mystical philosopher.

Yoel Regev: Yes, but here it should be underlined that this is, unconditionally, linked with the abolition of any kind of will or determinism. It is an approach without the figure of God, without the figure of the sublime. And it is also, properly speaking, a fundamental ontological revolu- 
tion, which must be achieved-to enable the notion of such a kind of reality without the need of any figure of some kind of directing entity, never mind what you call it: God, will, or law.

Audience member: Yoel, surely sex can work like that now, even if only in part?

Yoel Regev: Of course, insofar as some elements of the future communist society are already present in capitalism. It can work in this way, but its functioning is blocked in the contemporary conditions of existence by the fact that we can only with great effort picture such a sexuality as real. When I say this, what kind of thoughts appear to people? "Maybe it's all just a case of there being some kind of metaphor there; none of it is real." Precisely this "not real" must also, I believe, be changed as a result of the new economics.

Artemy Magun: This has an interesting resonance with what Oxana was saying.

Yoel Regev: Yes, absolutely.

Konstantin Shavlovsky: A brief question. Forgive me for interrupting, I just couldn't remain silent. How in general does what you are speaking of contradict the theory of polyamory? I am no specialist on it, but it's been a year now since lots of people have been talking about it. They talk, in particular, about each person being the center of their own polyamorous relationships. This is no kind of closed-off collective, moving away from society, like a commune sailing on a ship. This is just like what you are talking about-a path that each person follows for themselves, just that each person ploughs through their own reality in correspondence with their own trajectory. This is also polyamory in my understanding. center"?

Galina Rymbu: Perhaps here we are faced with the problem of the “

Konstantin Shavlovsky: Each individual is a center for themselves. Just as each individual is a subject. And that's all. There is no kind of collective subject. Perhaps there is, but this is already quite another difficult story.

Artemy Magun: Happy is he, whose center is in himself, but do we often meet such people?

Yoel Regev: In some sense, this goes against the principle of the multiplication of love. Or rather, it doesn't contradict it, but takes away from 


\section{Discussion}

it its fundamental quality. The main criterion here is: "However many challenges, so many partners." There is no need to increase the number of partners to the extreme, but neither is there any need to reduce it. On the whole, I think that future communist sex will preserve in itself-just like Bolshevism-leftist and rightist inclinations, and a general line which only actually exists in the form of manoeuvring between these inclinations. Doubtless, that which polyamory is aiming for will be present in communist sex, in a somewhat transformed manner. I just want to say that it might only realize this aim under the conditions of a change in economics. Only under such conditions will we truly be able to perceive the sexual act as the resolution of a certain task, as a changing of the self.

Artemy Magun: You can perceive anything you please. But how does this become the resolution of a task?

Yoel Regev: Reality itself must be transformed in such a way that its change is perceived as meaningful. That is, we probably are solving this task now too in some sense, but we are separated from this resolution because the current reality subjects this resolution to the alienating concept of what is real and what is not real.

When now we ask somebody what he is doing and he says: "I was clarifying," we do not take such an answer seriously in ordinary conditions. We ask: "Well, what exactly was it that you did? What did you make? What were the results of your clarification?" And that change of which I was speaking must be in the world which leads to the person clarifying taking the place of the person creating, as the central figure of this reality. Clarification is actually made ontologically existent and substantial.

It seems to me that there is present in polyamory, just as in the second inclination, a preservation of monogamy. These distinct challenges are not conflict-free. There actually exists a hierarchy between them. Each of them claims to subject the entirety of reality to itself. There exists a constant struggle between the different tasks, each of which claims to be the main thing, to be more important than anything else. This is a real conflict. It may be the case that it doesn't contradict certain forms of polyamory, but, in principle, insofar as I understand polyamory, it supposes that there cannot be any conflict.

Konstantin Shavlovsky: No. It would be foolish, of course, to think it possible that jealousy could be removed and abolished so simply. This cannot happen.

Yelena Kostyleva: Yoel criticizes polyamory for its utopianism: as though we say now, "we're ridding ourselves of jealousy"-and now it's gone! But at the same time, you propose another utopia in its place. Although I would say your utopia is, of course, more interesting, because 
really everything we know about polyamory is known merely from the basic rules of behaviour discussed within it. There is philosophy there, but, generally speaking, philosophy can be in whatever you like. And so it is there too-in connection with this, and in connection with that.

I was particularly caught on this point. The thing is, you spoke of existence, of ontology. I recently came across a quote from Lacan, in which he talks of how the dimension of existence arises in the flow of the discourse of the master. Linked with this is the fact that the very verb "be" is an imperative; I say that something is, and it will be. Or I say that communism will be, and it comes into existence. This is the discourse of the master, as it were, defining and postulating existence (according to Lacan). I turn again to the question of power, and, therefore, to that of love too. As Artyom says, the world itself is moving. Why, then, should I feel that it is me who moves it?

Galina Rymbu: It will be rather hard for me to say something decisively different after such passages, insofar as I see that the discussion is built around a certain tension between polyamorous and monogamous types of relationship. It seems to me that both these types of relationship are so suited to the logic of the present-day capitalist network society that to follow them in either a personal (practical) vein or a utopian direction seems strange, if not over-luxurious. Both these forms of relation in "pure form" represent a certain luxury within the dramatic conflict of love and politics that is becoming ever more visible today and leading to serious changes in the structures of desire itself, in the understanding of love. This is evident meanwhile in both the relationships of the most vulnerable groups - the poor and the precariat (to some partial extent) and the proletariat (which formally continues to uphold monogamy), as well as among the middle class and even among the elite, who may permit themselves such a luxury in the form of polyamory or various other forms of open relationships. Monogamy is already a luxury the former cannot permit themselves, as it is getting harder and harder to maintain the monogamous family and children in conditions of total poverty and social vulnerability. Open relationships are a luxury for the second group, although it seems they are able to indulge themselves. Indeed, if we are talking about marriages (including both the polyamorous and monogamous kinds), then it is barely possible to adhere to any discourse of innocence and feelings, as relationships are not just about feelings, but also about shared domestic life, survival, and struggle: time and money.

As such, the struggle for monogamy and the struggle for polyamory are not only an emotional struggle, but the fight against capital. And the latter is totally capable of accommodating polyamory, because it can be perfectly integrated into its logic: that of surplus and deficit. We understand that, in the modern world, both autonomous local units and multiple units or networks are profitable. And both will find their place in the 


\section{Discussion}

society of consumption (the "consuming" of feelings). Monogamous unions are associated with autonomy, isolation, and the desire to protect oneself against the superabundance of sex with which we are assailed on a daily basis by media structures, virtually by force. On the other hand, such a union also structures deficiency: the limitation of choice and freedom (with adultery becoming not less, but more dramatic) together with a shortfall of new "meanings" for such types of relationship, for their internal legitimation.

The various, more open types of union are moving towards the multiplication of pleasure, and to the creation for the sake of this of new connections and worlds. Partly because they haven't the strength to overcome the internal deficiency of meanings in monogamy, and partly due to their having been hypnotized, in some manner, by images of "surplus." But this movement is not dialectic, in my view, as it has no relief to it, but merely an obvious tension in readiness to tear down the "old world of Desire." This Desire is the platonic "spring of love," the illusory infinite, straining, one way or another, between the two ends of the finite: the Two that cannot be dismissed so easily-in this sense, even if you are a group of five and you have, at first glance, legitimate plurality, you will always be two. Not in the banal sense of two, by which all individuals ultimately end up sorted into couples, with some being left over, or that generally only two will "survive," but in the sense in which Badiou writes of this Two of love.

The "tension" of the spring of Desire is conditioned on the one side by openness and the desire for interfusion (behind which looms the shadow of the real), and on the other by a certain "encoded" impossibility, to which no One (the idealistic fused union) is granted private access. This is a cunning spring. It can stretch between two even in conditions of the total emptiness of sex, in the absence of sex and in the absence of a subject of love relations (and this has always been in some sense absent!). However, it seems that this tension cannot structure contemporary sentimentality any longer, and must snap or burst. But in some qualitatively different way, distinct from that disruptiveness which is inherent to it. And then love, in any of the understandings of it that are possible today, will cease to exist. That said, it is far from certain that we will get that society which Yoel speaks of: where every new partner (be it a man, woman, queer, animal, plant, or object) is a new challenge. It is possible that there will be nobody who could or would in general have to deal with this challenge.

I myself tend to think that, ultimately, everything which concerns feelings for another is some kind of 'mis-challenge' (in the sense of the Russian expression rendered into English as "tough luck!" [but translating literally as "what a non-task/challenge (i.e., misfortune)!" - translator]). Any task supposes finality, and in any teleology there is a return to the start, in the same correlative circle (or fractal too) and partially projective logic. What is obtained is that everyone here who has been my 
lover and challenge returns to me (as in Cohen's song) - this is the Apocalypse! And, nevertheless, I see in this network logic something more complex, more conspiratorial, and more conflict-ridden and tense, but how revolutionary is it? After all, when we imply that an other, that love, is a challenge that can be resolved, then are we not dissembling?

I believe that nothing can be solved in the (new) love, and you cannot solve anything here at all, as love does not exist to be solved. The logic of determination is the logic of force. I would suggest that love beconsidered generally beyond this coercive logic of determination. Not that I am opposed to leftist militancy, to struggle, politics, or decisions. But it seems that if in this sphere (of sex and love) something in particular is permitted, then it will inevitably be opposed with force: in some kind of sense like that in which Sorel opposes force as the order of violence (the proletarian strike, smashing this force-based order). If for some reason we need love for another, then this is in order to constantly subvert and cast doubt upon the entire hegemonic dialectic of resolution by force and its operational aspect.

It is very difficult to reject love as force, as everyone knows that love is what gives us this force, the inspiration to take and enslave Troy (and here, of course, is where the root of evil is found). To tell yourself today that love is a matter of the affirmation of powerlessness, is possible, and is the selection of the revolutionary path, which can also be a tactic of opposition. This Sorelian combative pessimism, which I suggest be transferred to the love experience, opens up many possibilities. Is there a place in it for romance? For me, the extreme model of romanticism is the atomic bomb female idealist. You wouldn't like to give her flowers (do you remember pacifists with flowers? but this bomb wants it anyway-flowers and kisses). Romantic love and the atomic bomb are linked in a strange way. And I wouldn't want to have anything to do with this.

As for courtly love as a whole, I think that we all feel to some extent that it is impossible to find ourselves in such love, this subject is lost. Its establishment coincided with the pumped up worldly God, and against him (it is characteristic, incidentally, that the troubadours soon died out, being gobbled up by Luther from the future). What we have today is the ephemerality of courtly love. Here one might recall Meillassoux's "Spectral Dilemma": the strained ephemerality of the modern day world arises due to the fact that we are already unable to live as though there is a God, but we cannot live as though he doesn't exist, and so Meillassoux suggests that we live as though God doesn't exist yet. This is very similar to love in the utopian (Bloch) and in part in my own understanding: the subject of love, and indeed anything else besides, is he who is not yet. But now I don't want to love this phantom, I don't want to reconcile with it, I want to love your body, but, hey, let this not be the body of Christ. To have the powerless sex of today while not ruling out the possibility that something else might appear. 


\section{Discussion}

Konstantin Shavlovsky: A strange critique of polyamorous pleasure, as pleasure through powerlessness.

Galina Rymbu: It's not pleasure. It's me, powerless before you.

Artemy Magun: This might also be the obsessive type of love we have already mentioned.

Yoel Regev: Very briefly on two points. First of all, about the subject and the challenge. I absolutely did not have in mind that there exists some subject who solves tasks or challenges. On the contrary, the subject is only defined from this continuum of challenges which he deals with. That is, I am also that whose content is changed each time by the new tasks with which I am faced. Secondly, of course, it is quite unclear what kind of challenge this is. In general, the main challenge is to understand what kind of challenge it was at all. And the resolution of this problem is the understanding of what it was. But as soon as we have solved it, it disappears and its place is taken by another.

\section{Artemy Magun: Has everyone spoken?}

Oxana Timofeeva: I still have a comment to make. I would like to warn against the notion that we are discussing some kind of actually existing choice between two types of relationship. In actual fact, I suggest that we are not faced with such a choice, insofar as both are equally impossible. Recapitulating that which has been said, in the context of the specific given capitalist relations, intimacy itself with another person or persons is problematic. Which is truly significant, as it informs the way in which we approach this problem, and the approaches we take towards working out its solution. The solution proposed by Lena is linked with the constant transformation of the subject, which must be realised immediately through certain experimental practices in the organising of love relations. Yoel says that it is first of all necessary to transform society, to provide the corresponding socioeconomic conditions, and moreover create such an ontology in which a new subject might appear, in order that new feelings may be experienced.

In principle, I agree with this latter general line of ontology and socioeconomics. If it were radicalized a little, one might end up with having first of all to build communism and only then to make love. Rather like how some of Andrei Platonov's heroes behave-literally holding themselves back from any intimacy, until they have built a happy society. On the other hand, what makes me uneasy in Yoel's position is that this is some kind of futurism. My own vision of the future, my vision of communism, is linked with the dialectical retrospective, from the moment of remembering or forgetting, looking back. I don't believe in a future subject, 
but in that which exists now with all its jealousy, suffering and powerlessness, with its alienation, with its unconscious ancestral memory and negativity, the potential of which has not yet been discovered. It is precisely on the side of this ancestral memory that I place the horizon of the communist society. In speaking, say, of romantic or courtly love, I have in mind that other side of these relations which never developed itself, feeling too cramped on that marketplace. The one in love, the one green with envy, kills the beloved in the fit of passion, but the very same jealous man writes In Search of Lost Time creates works of art, or flies into space-his desire finding the most varied paths of release.

In her time, Alexandra Kollontai made reference to the example of mediaeval courtly love as a kind of rehearsal for the communist love of the future. Her idea was that we have not yet built the socialist society, we haven't got the capability of truly arranging sincere love relationships with our comrades, though courtly love has been given to us as the possibility of preparing ourselves for love-comradeship by means of play, ritual, and the performative arrangement of the outlines of potential relationships linked with winged Cupid. That is, we are already in possession of models for something suitable, and on their basis we might build something new.

In polyamory as a positive programme, which seems more realistic because it doesn't demand the transformation of society, never mind that of domestic life, but merely a reformation, properly speaking, of the traditional institution of marriage, I am troubled by that aspect referred to by Lena as inclusivity and openness. Everybody understands that inclusivity and openness are good, and that exclusivity and closedness are bad, because contemporary liberal democracy teaches us that it is compulsory that everything be open, just like the German parliament: you can see the dome of the Reichstag, and can even, perhaps, look through binoculars and see Angela Merkel opening her mouth. The subject of an open society is put on show. And so the unrealised potential, in particular, of romantic love is, in its own way, set against this imperative of total openness and rationality, though its opposition is seen as evil and associated with danger, deception, and lies. And the human being intuitively explores this side of morality in order to find there the element of opposition to this society in which all is put on show, a society, on the one hand, of liberal democracy, and on the other, of capitalist injustice, where everyone is alone. Yes, here all is open, but give me back the right to secrecy, to my own internal "evil," following the hysterical roads of which I might, perhaps, meet that special other or those others, to meet my love.

Galina Rymbu: I would like to add one small retort. It seems to me that when we speak of some kind of monogamy, of some kind of love between two people, we sometimes forget that this love between two doesn't exist. In any relationship between two people there is always a virtual 


\section{Discussion}

third, fourth, or fifth; they are many. And so, if at any moment it turns out that you are left alone with your partner, it means you go out of your mind. A pure couple is simultaneously a situation that is perverse, mindless, and cannot in general exist at all. On the other hand, this gives new understanding as to why some "couples" do not find years or decades together boring, even without children-perhaps they have something to talk about with their many. This is all an old-fashioned lie: there cannot be a relationship between two, because there is no such two. It's simpler to remain single.

Artemy Magun: But then it must all be approached in a different way. That is, if we accept that the dyad is impossible, then what is all this ritualized rhetoric on committing to one another for...?

I wanted to answer Oxana too. In what you say, there is both a conscious and an unconscious layer. You say that you are against polyamory because there is such a thing as jealousy and so on, but jealousy itself is concealed polyamory. Freud's famous analysis of the case of Dora demonstrates it: it seems that Dora loves an older man, but if we dig deeper, it is revealed that she loves his wife. She cannot express this feeling, she simply cannot accept it. And so she projects her love in a more standard manner onto the man, while feelings for the woman pour out contrariwise-as jealousy. Feelings of this kind actually demonstrate the impossibility of the dyad. But the dyad nevertheless is there!

The issue here is not that we are all, "when it comes down to it," polyamorists, but one of institutions, that is, the issue of how to formalize this. That's one point. And the other, following on from this, is of a practical nature. What is it, actually, that is being proposed? There is, say, a specific institution-the nuclear family, which is not simply monogamous. There's a certain structure of society which is composed of households, involving a mum, a dad, and two or three children. That is-the elements from which our society is built. But this is a relatively new phenomenon, which was consolidated at the earliest in the twentieth century. What's more, the very character of the nuclear family has continued to change since that time.

Whether we talk of polyamory or the search for a new moral partner-we either leave this structure or replace it. If we replace it, then I would be interested to hear from the aficionados of communism-how? As is well known, the communists initially considered the institution of wives in common. The answer of Marx and Engels in the Manifesto was thus: on the sharing of wives in communism we know nothing, but we know that the sharing of wives has already begun among the bourgeoisie, as adultery flourishes among them. What do we need polyamory for as well, when there's already adultery? Engels says that if it already exists, then it is simply necessary to deduce the facts in accordance with theory. That is, in principle, they supposed at that time something akin to pro- 
miscuity, but were later disappointed. Engels himself lived in concubinage with a working class woman whom he never married.

In actual fact, that which you are all now saying about sex is quite characteristic. Sex is, of course, very important. But it remains the filling of some institution which is, primarily, the family, and secondarily, extramarital connections outside the family. Two institutions or two sides of the same institution. And then all subsequent feelings arise for this same reason. Love is nevertheless usually examined as connected in some way with the idea of cohabitation. In principle, there are strong arguments that, perhaps, all this is correct, and the nuclear family is natural-children have to be raised and so on. On the other hand, what is wrong with adultery? This is even interesting. People are lacking a bit of spice in their life, and here they skulk away from the well-lit space of public life and concoct secrets...

\section{Oxana Timofeeva: No, I wasn't talking about that at all...}

Artemy Magun: I have a more simple view. You are all here very intelligent, highly cultured authors. And yet I would like to know what it is that you plan to do right now. Today, tomorrow, next week, in a year's time... when your party comes to power or doesn't do so, if, perhaps, it is fundamentally opposed to that.

In my view, a transformation is needed of the current institution of family/love. This is an incorrect institution. It actually ignores, as you have said, certain things that unconsciously exist as part of it. And, apart from that, it is strongly bound up with the emotions of two people. But who said that two people is the optimal group? At face value, three would seem more fitting as the ideal group-tres faciunt collegium, and in such a group the arbitration of conflicts is possible. Families, which are more or less happy, are saved by the fact of children, as the children grow and form a kind of love triangle. This must not be forgotten: for children are also objects and subjects of love.

A triad-what is that? An uneven structure which is often referred to as a "love triangle." This means that there is a dyad and a third somebody turns up. And then everything goes far from swimmingly-as the third party here is not something completely external. It enters into certain highly complex relations between these people, and these relations are not always blissful. This leads either to the breakup of the family, or to its extension. This triangulation of love is actually taking place constantly and, as it seems to me, may give rise to genuine social connections, although in its present form it is more a negative, destructive force.

I've even written something about this in the book Unity and Solitude. Two persons cannot be found in solitude if they are together, because they are always bound to one another. They look at each other: hence Sartre's famous notion of the objectifying glance-if another looks at you, you are 


\section{Discussion}

no longer free. And what, if in this situation there is a third person, looking on when one is looking at the other? In theory, this might have an emancipatory significance.

Dmitry Vilensky: But Artyom, there isn't always another person. Do you recall Brecht's “dritte Sache," or his "common cause”?

Artemy Magun: Oh yes. But now we are talking of social relations.

Dmitry Vilensky: He introduced precisely that, as the "third thing."

Artemy Magun: That is a separate conversation, and very interesting-insofar as joint activity can dismantle that moment of the brief fastening of two personalities. Perhaps. But if we look at the relations themselves, then, as I have already said, collective loneliness, that is the moment of a person's return to his own open (free) existence, is possible then and there, when a third person appears in these relations. I repeat, this usually works via children, but it is not fixed that it can only be through children. And it is clear that such a system is unsustainable.

One other point. The thing is that it is no mere matter of chance that the nuclear family forms the foundation of capitalist society. This is after all a very atomised society. But it is not the case that these atoms suffer totally from their negativity, they don't feel as though society is completely broken down (into atoms). The atoms are still united in molecules. Like, for example, the water molecule $\mathrm{H}_{2} \mathrm{O}$ : dad-mum-child. As a result, society itself is not quite found in fragmentation, but in more of a liquid state, and as such is very convenient for those wishing to pour it this way and that. Very convenient, for the state.

What is it that we have here? We have these intensive emotional connections on the level of the dyad (or the triad-tetrad, plus children). We also have, of course, civil society. But what exactly is civil society? It's the non-profit organization, and in a wider sense the profit making organization too, that is, business organizations as organizations with rather weak emotive connections. Of course, there are interesting contradictions there, when emotional links appear anyway (and they do so appear), when romances start or strong friendships are forged, and you can hear businessmen saying the likes of: "This friendship threatens our association, because we are all involved in the same business"; or, conversely, that capitalist relations are breaking such friendships, and have to be kept strictly apart from friendship and love. Indeed, there is a struggle against emotions in organizations, and if such connections arise, they do not go on to form a powerful collective fist. Why? Because emotions are evacuated in the private sphere, and the private sphere rests on the dyads.

In this sense, of course, the arrangement of a society composed of large communes would be much more interesting politically, in the sense 
of freedom and democracy, and the sense of the distribution of power in society-a more or less even distribution. Far from this is the present day watery expanse, with the Noah's Ark of the nation-state floating in its midst... Such that there is something to consider here in the sense of the reforming of society. As for sex, so beloved a topic of yours, then this, I repeat, is another question. First of all, organize an institution. And then decide how sex will happen there. Although, of course, it cannot be abandoned to run wild, either. Because, if you leave sex unattended in a commune, you get Otto Muehl.

Dmitry Vilensky: That is, in natural conditions, everything goes straight towards the structure of the harem?

Artemy Magun: Yes, that's how it appears to me. At least there is a great risk of this. Naturally, I have no well thought-out plan. It cannot be stated firmly that only monogamous families may live in this commune, that they will meet just in the kitchen and while carrying out various tasks together, bringing up children, will only have sex in couples. In principle, this is a possible model. It isn't at all compulsory that a sexual revolution be organized in order to build a commune. But in reality, this usually isn't what you get, of course. We all understand that network-based emotional ties, if they form and we do not interfere with their formation, can lead to polyamorous structures.

It seems to me that, just as in the case of ordering a society, we need here to come up with some kind of symbolic system, which would make these types of relationship interesting and rational. It's the same with democracy-it seems to us that democracy is either that fiction which we have today, or that it is simply a mass of people who decide something together. And when we say "More democracy!" we picture to ourselves this mass of people deciding something together. And it's the same with sexuality too-either it's the traditional nuclear family, or some mass of people freely, like atoms, forming large molecules. But such concepts are quite inadequate as an understanding of democracy. In its original classical form, democracy is, first and foremost, the drawing of lots. That is, a system in which there takes place the symbolic mediation of power in the shape of the ballot. And then, as Aristotle teaches us, a rotation occurs: you cannot be found constantly in either a subordinate or commanding position. These must alternate in some way. It's a game. And it is precisely this democratic system that has been forgotten and left aside by the politics of the late modern era.

There is, in Lacanian terms (forgive me), a régime de l'imaginaire. A regime of the imaginary is the same as Otto Muehl's commune. And above it there is a regime of the symbolic, where the neutralized symbol permits the retention of diversity and pluralism of relations, the pluralism of connections, and so on. If the utopia of the family and sex can exist, 


\section{Discussion}

it needs to have just such a complex constitution. Just like the Marquis de Sade in his anti-utopias. It was cruel and hierarchical there, but who is preventing the organization of a more emancipatory aleatory system of communal life?

\section{Dmitry Vilensky: And in Zamyatin’s “We”?}

Artemy Magun: I also thought of him. Zamyatin has symbolic mediation. And thus, in general, it is necessary to reread him, and see where the utopia is and where the anti-utopia.

And so, in these communes, I think, sexuality must be subject to a certain aleatory symbolism. But, I repeat, in this we are not only dealing with sexuality, but also with shared habitation. Why in general have love and sexuality become our main emotions, and why is it that we are always talking about them? Specifically, because the institution of cohabitation, and social connections in general, have ceased to be mediated symbolically. It is unclear why people need them. Nothing is restraining you in either a marriage or in a free relationship. There is no tradition, no moral norms. And it is precisely due to this that the conversation is always about emotions and about sex as their material guarantor. Olga Meyerson wrote not long ago on Facebook about the latest legalisation of gay marriage in the USA, that the problem is not one of marriage as such, but that there is less and less opportunity for people to live together, hold each other's hand, or even just converse for an extended period with a person of the opposite sex without this taking on a sexual connotation.

What, then, is the problem of contemporary love (in my previously mentioned "obsessive" version)? It lies in the fact that they assail you with love wherever you are, and that you are constantly supposed to be loving somebody. But why? Because otherwise the institutions of everyday sociability cease to function. These institutions are so weak that they are propped up nothing but affect, on the constant reproduction of affect. And in real life, as we know again from Lacan, true love is not an affect. True love is a gift, a certain act which might subsequently give rise to affect and so on, but affect is simply a means of feeling it. And this act, I repeat, must be reinforced symbolically and institutionally. Our life is passing through a crisis of symbolic institutions. This is yet another Lacanian thought that I share. And so some new institutions need to be devised. It's another matter-in my opinion-that these cannot be of the pure type as in traditional institutions. They will have to be invented anew, because the theme of the family and love is a nodal, core point of contemporary society, precisely due to the fact that, today, all the affect in this society is concentrated right there. Including macropolitics, insofar as nationalism, as Reich demonstrated in his day, signifies exactly this imaginary projection of the affects formed in the nuclear family onto wider society. And this is not at all the way it has to be. It is vital that the af- 
fects of large collectives be kept apart from the relationships of the individual.

And a final thought. Historically, as Yelena Kostyleva rightly states, the cult of love as the sole and forbidden passion is linked, of course, with Christianity and with that which we have now got in place of Christianity as a symbol of faith, the love for another person. This is, of course, remarkable-Feuerbach formulated it back in the nineteenth century and gave it his seal of approval. Although this somebody we love is not God, but another human being. But in the process of this transformation some distortions were produced. The point is, Christian love, $\dot{\alpha} \gamma \alpha \dot{\pi} \pi \eta$, or caritas in Latin, is not the erotic at all. We surmise that the female mystics of the Middle Ages actually experienced orgasm when they thought of God, or else we might remember the troubadours, who borrowed mystical discourse in making songs of love. But again, this is not the issue alone. Aүó $\pi \eta$ is, funny as it may be, group love to a T. Christianity was more polyamorous than the contemporary discourse on love, which adds the sentimentalism of the nineteenth century to Christianity. From the outset, there was this openness and plurality in Christianity, though it was conceptualized primarily not as erotica (although it can be regarded in this way), but as caritas-care and giving. You give yourself to people, and

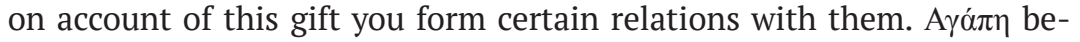
comes your bond with God, but also that tying you to other people. And it is asymmetrical, because God gives himself to many, while each loves God separately.

What do we have today? This structure of caritas-that of caringstill exists. Where? That's right, in the state of general welfare, the welfare state. Here is where caritas lives, but it is quite unemotional. It's a neutralized, emasculated form of caritas. And, as we have seen, Christian love itself is crammed solely into the dyad or triad. What is this exactly? This bifurcation is, firstly, a mockery of the concept of love, and secondly, it is, of course, a cunning move of the state and capitalist elite geared towards the liquidation of resistance in society. And it is all propagandized in mass culture.

I would like to end with a nod to cinema. It seems to me that the $\dot{\alpha} \gamma \alpha \dot{\alpha} \pi \eta / \tilde{\varepsilon} \rho{ }^{\prime}$ or caritas/amore collision is seen very insightfully by Lars von Trier-being one of his main themes. Several films, Breaking the Waves and Dogville first and foremost, are based precisely on this collision. Women, instead of quietly making love with men (or other women, OK), suddenly start engaging in charity! They feel that they are the Lord God and go out and, crudely speaking, have sex with a large number of people, not loving them in an erotic sense, but loving them as people, giving themselves to them. They take on the role of Christ, $\alpha \gamma \alpha$ d $\pi$. But what is this? It's Trier's critique of the domination of the welfare state. He seems to be saying to the representatives of this state: "What you are doing is helping other people. But you don't do it seriously and do it without any feeling 


\section{Discussion}

whatsoever.” And, as I have said, by doing this, you evacuate Eros into the dyad. But Trier's women are greater than the dyad, they don't want dyads, they want to love everyone, and they feel, they become infected by this society of distribution and universal welfare and wish to accept it all in full seriousness. As a result, their own sexual activity loses all sentimental and personally enriching meaning.

Almost all of Lars von Trier's filmography (we will mention Dancer in the Dark and Nymphomaniac too) is a travesty of the welfare state, an attempt filled with its meaning but in such a paradoxical and tragic form that it breaks down. And there you have the communist revolution, by the way, in caricature. In this context, he is a very important director and leading analyst of contemporary life, although, of course, to put it bluntly, he is no political ally of ours: in observing an existing contradiction, he makes from it a series of pessimistic and even, rather, reactionary conclusions-particularly in his latest films, in striving to overturn sexuality as such, as something disappointing hope. This is not our path...

Nikolai Kofyrin: Continuing with film, it was not long ago that the world-famous film Fifty Shades of Grey came out. In connection with this, I would like to hear the opinion of the philosophers on the topics of BDSM and LGBT. I'd like you to analyze these two fashionable new phenomena, which understand love not exclusively as sexual attraction, but as a way of relating to the world, in which sexuality and carnal love are only a certain transformation of this greater love. As a derivative, and not the reverse. You are, as it were, looking at the world from the perspective of carnal love. But I am talking of how carnal love is only a particular case of universal love, of love as a way of relating to the world. From this point of view, I'd like you to give an answer on your understanding of BDSM and LGBT, as well as on homosexual families - nuclear families, but, forgive me, homosexual ones.

Yelena Kostyleva: Well, what's the difference, if it's nuclear anyway? As for Fifty Shades of Grey, I haven't seen it, but I read a little of the book in English. It's very badly written. The thing is, it's a woman's novel, a novel for ladies. With one single alteration-instead of scenes of tender lovemaking, it has scenes of BDSM love in it. And the fact that it has prompted such a gigantic resonance, in the billions, tells us that the concept of romantic love with tender scenes has given way to a concept of, say, romantic love but "with spice," "with a spark." There is nothing interesting here. It's purely a social phenomenon. Unfortunately, I am forced to say, it's cinema for women. I wouldn't attempt to find anything ontological in it. This is an answer to both your questions.

Oxana Timofeeva: It seems to me that what is truly curious in the contemporary phenomenon of sadomasochistic love is its deeply Chris- 
tian nature, linked with the sufferings of Christ, with the Inquisition, and with the technology of torture. Productive relations and the means of production have reached the point today where it is possible to bring Christian dreams to life, thanks to a variety of sexual practices and technologies. In BDSM, sin and redemption coincide in the same act.

Yelena Kostyleva: As suffering the Passion. BDSM as suffering the Passion.

Oxana Timofeeva: On the one hand, as Slavoj Žižek puts it, there exists in the contemporary world the capitalist imperative of pleasure (enjoy!), while on the other there is the Christian imperative, linked with suffering. Christianity and capitalism meet in the BDSM commune.

Nikolai Kofyrin: In other words, love is suffering?

Artemy Magun: From the point of view of Christianity, as Oxana has said.

Nikolai Kofyrin: BDSM is also suffering.

Oxana Timofeeva: Both suffering and pleasure-the combination and union of suffering and pleasure. tion.

Artemy Magun: Well, that idea is clear enough. Give us another ques-

Nikolai Kofyrin: What about LGBT?

Artemy Magun: I can say something about LGBT, if it's so important. And actually, this topic is rather significant, and draws a lot of attention today because, although homosexual marriages are taking place, there is a qualitative difference between homosexuality and heterosexuality. Homosexuality breaks the logic of the dual pairing of erotica and so it is not by chance that the traditional coupling behaviour of homosexuality has been characterized as promiscuity. The idea of a homosexual married couple is something rather new and doubtful.

Nikolai Kofyrin: And is platonic love homosexual?

Artemy Magun: Well, sort of, yes, though is it important? In any case, behind the modern-day fashion for homosexuality there stands simply love for people, for everyone, including those who are the same as yourself. The homosexual is one who has understood that, under the envelope of any individual attraction, in which you, as it were, recognize your self or 


\section{Discussion}

your alter ego, you simply love people. People as they are. On this, see for example Pasolini's Teorema. But in homosexuality, this protest against love in a couple and personal love is resexualized and leads back to the nuclear understanding of relationships.

Dmitry Vilensky: Is homosexuality not love for the self?

Artemy Magun: No, it is not the self (your mirror image) that you love in homosexual relationships. That would be a narcissistic interrelationship. But homosexuality is when you love someone who, yes, is the same as yourself, but as another person.

\section{Oxana Timofeeva: This is questionable.}

Dmitry Vilensky: On the contrary, Artyom, it's more the other way round (according to Freud). In homosexuality, narcissism is more expressed.

Artemy Magun: Very well. This is a disputed issue. It is clear that in the twentieth century, narcissism is found in all relations. There is nothing without narcissism. But the fact that these two logics-the heterosexual and the homosexual-have met, signifies that there is a different type of love for another. I like Žižek's idea, from his recent book Event, on how the secret of heterosexuality-is homosexuality. Under the mask of another gender, of something beautiful and exotic, under this cover, you still love something the same as yourself, regardless. The essence is that, under all this tinsel of gender and narcissism, there are concealed relations of the loving of people (philanthropy, as they called it in the twentieth century).

Oxana Timofeeva: I'd like to suggest a compromise. I am in partial agreement that it is necessary to build an institution. I don't defend institutions that are five hundred years old for the sake of it, no-I am also in favor of new forms. I simply consider that when you speak of building an institution, you are supposing a state too, but not a state as the repressive machinery of absolute evil. We will allow that the state has an interesting dialectic, containing within it ambivalence and a constitutive impetus. And this same constitutive, progressive impetus may exist in sexual relations too, even as part of the monogamous family-of the "official" form of love.

Artemy Magun: First of all, "we" in this understanding would likely have had to seize power, because without it nobody will allow "us" to restructure institutions. This is a joke, of course. In reality, it's clear that nobody will give us power. But it is through such things as they seem to be 
left to be outsourced to human spontaneity, that influence might be exerted on society, through these something may be done and nobody is actually preventing you, Oxana, from making some kind of experiment with love. And perhaps through this you may change something. Or Yoel, who also suggested this. You might even begin tomorrow.

Yelena Kostyleva: But you prefer without experimentation, so surely...

Artemy Magun: Oh no, I'm all for experiments, and all in favor, like Chernyshevsky, of building a commune. I have a completely practical notion of it. Nobody has forbidden it yet.

Oleg: But, well, what are you creating for, that's the question, no? To reject love or obtain a new one?

Artemy Magun: Both one, and the other, most likely.

Konstantin Shavlovsky: It seems to me that change in love and change in society must go hand in hand. You can't say that now we're going to change society first, and only then love, or first love and then society. It's a dialectal movement, as it were, do you not agree?

Artemy Magun: In general, these themes are central: on the one hand, we have the pushing out of all affects, farming them out into the private sphere, and on the other, look what's going on in politics-for there you see a perfectly conscious play on the simultaneous suppression and sublimation of supressed emotions, all just as Reich said. That is, sexuality is actually "lifted up onto a shield," if there is anybody who hasn't noticed the last few years in our country. In this, they have left that real sexuality-not the suppressed kind-left it to be farmed out: "Do what you like there. Mess around, it's not our affair." Just don't bring it out in the public sphere, because we have repression in action there. This is the point of ambivalence, and it has to be taken advantage of.

Olga (Tsaplya) Yegorova: I'm sorry, I was late, and it seems I've missed something. Has love already been finished off? Are you starting out from the premise that love no longer exists?

Artemy Magun: Oxana, on the contrary, started out from the premise that love hasn't yet begun. much.

Olga (Tsaplya) Yegorova: Ah, I see, not yet begun. Thank you very 


\section{Discussion}

Audience member: Might we examine how the brothels for the proletariat of the late nineteenth century became the communes of the early twentieth in Russia?

Artemy Magun: I know nothing about brothels and leave that on your conscience, but it is true that, the 1920s were a heyday of such experiments. And not in the sense that they were initiated "from above," but rather that people spontaneously decided that, now we have communism, let's restructure our relations. That is, there were precedents, in the thousands, scattered all across the country. There's a book by Richard Stites, who documented the presence of these communes in some detail. Some of them would collapse of their own accord, but then came Stalin and shut them down, like much else besides. And so we do have precedents for a commune.

Yelena Kostyleva: I will clarify something about polyamory. We are simply discussing it as though it were in itself a revolutionary practice. But there are different forms of it, and they are many. At its roots it is absolutely bourgeois-this is the form for people from the middle classes with higher education and decent level of income. But there is also that twist which would be of most interest to those of us assembled here-the utopian version, the revolutionary. Such as the queer movement in polyamory, for example. What might it lead to? Might it smash capitalism? I just wanted to make a correction that you cannot talk of the entirety of polyamory in the same way as we might talk of Kollontai. Kollontai was a hundred years ago, she was a revolutionary, yet these people, on the whole, can be non-revolutionaries too.

Oxana Timofeeva: I have formed the impression that, within contemporary capitalist relations, polyamory is a normal bourgeois practice.

Yelena Kostyleva: In principle, yes.

Maria Kochkina: As I understand it, two perspectives have been presented here which can be brought together. It seems to me that two things are understood under the emancipation of sexuality, which can be intermingled. On the one hand, we speak of the emancipation of sexuality, while, on the other, of emancipation through sexuality. And everyone, it appears, wants the emancipation of sexuality, and everyone agrees that emancipation through sexuality has not yet been achieved. The sexual revolution was criticised because, even if we practice various, at first glance, subversive practices, this all takes place within oedipal terms, and so we keep coming back to the same thing.

From this I make the conclusion, and it has been said before, that the base must be changed-primarily that of productive and social relations- 
for us even to have the possibility of sexual emancipation. There may be doubts as to whether, once the commune Artemy Vladimirovich has spoken of is built, emancipation will take place there, insofar as the people in this commune will be people of their time, of their generation. It is possible, however, that children will be raised in such communes whose practices might go beyond the bounds of the oedipal structure, breaking out into the universal through brotherhood, sisterhood and so on, and that for them this emancipation of sexuality will be a possibility.

Artemy Magun: In other words, we cannot remake our sexuality?

Maria Kochkina: We will always, of course, return to the same thing.

Artemy Magun: Well alright, because you believe Freud and Lacan, that sexuality is established in early childhood and at that point the affective structure becomes more or less fixed.

Maria Kochkina: If we are speaking of the emancipation of sexuality-of sexual revolution - then everyone who could do so has already criticized it. Foucault speaks of the dispositive of sexuality, and Deleuze of the oedipal terms through which you cannot break. We are all built into this structure, and cannot emerge from it.

Artemy Magun: Deleuze here, in my opinion, has a different stance than Foucault. He believes, rather, in some kind of emancipatory transformation of sexuality.

Maria Kochkina: In general, it seems to me that believing in sexuality's capacity by itself to do something revolutionary-means remaining in the bourgeois world with its forms of sexuality.

Alexander Pogrebnyak: Deleuze spoke of the desexualization of the erotic.

Oxana Timofeeva: But there can also be emancipation from sexuality.

Maria Kochkina: Yes, I think that, once that generation arises which can free itself from the framework we find ourselves in, there will either take place the sexualization of everything, or the desexualization of everything. It may be the case that this is one and the same thing-it's unclear.

Alexander Pogrebnyak: Many pretty words have been spoken here: communism, utopia, and so on. In agreeing with all this, feeling a sense of solidarity, I would like to make some critical points. Everybody reckons that Plato penned his Utopia as an ideal state, but in it, in actual fact, 


\section{Discussion}

a great anti-utopia is organized, when he describes the transition from aristocracy to democracy. In essence, with Plato, aristocracy is authentic democracy, in the sense that the aristocrats come to be selected by lots. But when this selection by lots begins to stir feelings of injustice among certain people-yes, in Plato it was the women: "Why was my husband not selected?"-it is then that all manner of cunning entanglements begin and, ultimately, we know where this leads. It leads to tyranny. To tyranny, including that of the nuclear family. In this sense, it seems to me that to speak today of how in the ideal, in a political project, we must aim for the resurrection of democracy with its aleatory mechanisms, choosing of lots and so on (Baudrillard writes much on this in his "Seduction"). This is all very nice, but begs a big question.

The matter is that in the model of radical democracy with its mechanisms for random selection, there will always appear an affect among those who simply never win the toss. The casting of lots is the kind of joke that before which, as long as we merely discuss it in the abstract, all seem to be equal. But when we are actually in this game, when we wait and wait... while life goes on; and nobody has suggested that we first solve the problem of eternal life, before thinking how a model democracy can be built within it. In this sense, it seems to me that the family-namely, the nuclear and bourgeois family-for many real people, and for many long ages, might have been the only possibility afforded to withstand the injustice of this distributary mechanism which, as we know, if it has even been realized-and on this point neoliberal ideology always places its emphasis-then it has been realised in the market. The market, properly speaking, is also this "third" which is constantly problematizing us and keeping us from reaching any final destination. Hayek says that a value must not be fixed, but must always "remain in motion"-not resting on anything. It is precisely because of this that Hayek says we must guarantee people's property. Artyom, it's good that you referred to Trier-but I thought that if we watched Breaking the Waves back to front, we would see not the fantasmatic project of the literalization of caritas but the contrary-a realistic picture of how contemporary society has been constituted. And precisely this: we have a woman whom everyone "has"-moreover, they "have" her "in the bad way"-a gang of sailors from a ship, while they anathematize her at home for this, and so on. And the sole way in which she is able to find refuge from this openness is to say "Let him be an invalid, let him be bedridden, but he is still my beloved husband.

As such, reading this film back to front, we see that, in some sense, the nuclear family is in fact dialectically ambivalent. On the one hand, it is called bourgeois and so on, but on the other, why do people create it? Because it is the only thing that is guaranteed to them. It's almost like in Freud, who writes in his Civilization and Its Discontents that the madman is he who invests all of himself into one thing. Your libido has to be actively shared out between several banks, including that reliable bank 
where the family is built, and when they "pull a fast one on you" at various other places, here at least is one place remaining for you. And how to get by, once you have a family, once you have set yourself up somehow in this life, you have work, that is, you have some kind of "dyad"... When I sit in the "dyad," I feel cramped, and I begin to dream of "triads." But at the point when people have only got hold of their "dyad"-like getting a flat in the Soviet era-you cannot start telling them that they have gone bourgeois and so on...

I repeat once more, as soon as speech goes beyond philosophizing and moves onto some kind of project building, it seems to me that that the dialectic point here consists of the fact that movement goes in both ways, and it cannot be said that one is unambiguously revolutionary and radical, and the other is necessary conservative and counterrevolutionary. This is a question for Artyom. And here is another brief question that I have drawn out to great length!-I have lots of questions, actually. Oxana, I didn't understand very well, but one idea was very curious: In communism, in a communist society, jealousy will not be less than in contemporary bourgeois society, but more?

Yelena Kostyleva: I will answer very briefly. That's great, if your husband is an invalid. Some women find themselves in simply unthinkable situations: where to run from everyone? And you suggest that she live in a nuclear family with the violence of another. May be this is better in some way, but I wouldn't...

\section{Alexander Pogrebnyak: No, I didn’t suggest that...}

Yelena Kostyleva: It's just that your concept is somewhat monogamous and somewhat idealistic.

Alexander Pogrebnyak: I myself am in perfect agreement with you, but was just trying to produce a possible counterargument from that side which we are all criticizing.

Oxana Timofeeva: In answer to the question on jealousy: if you imagine a society free from social and class antagonisms, but preserving, say, the antagonism of love, then in this "pure" situation a concentration of some affective energy is possible, the movement of which cannot be directed off into some absorbing channel (for example, in dull wage-earning or the even duller consumption in which many now find their comfort).

Alexander Pogrebnyak: That which Freud referred to as the narcissism of minor differences, I understand. That is, material problems are all solved and so part of our energy splashes out... That's all, I understand. Thank you. 


\section{Discussion}

Artemy Magun: I would also like to add something about jealousy. I agree with Oxana. Jealousy is, as it were, the foundation of love, its scheme, as it were. And what's wrong with it? Maybe more jealousy is needed?

Alexander Pogrebnyak: This is property. Its coerced form. But there is another jealousy.

Oxana Timofeeva: I am not talking of jealousy as property. Besides jealousy as property, there is another kind...

Alexander Pogrebnyak: I meant to say that property relations give rise to jealousy as one of the forms of its resolution. People begin to compensate this force of jealousy, in essence divine, with property. Or will jealousy under communism be such that this doesn't happen? When I see that I love her, and she doesn't love me, then, well, I don't know, I go and build an enterprise, take on workers... Marx criticised Proudhon in this way: if you don't abolish this, this and that-and we can add jealousy to this list-it will all come back again, capitalism in its entirety.

Oxana Timofeeva: Jealousy, death, disease, unrequited love-because of these, the whole wheel of injustice is ever ready to turn back and start it all once more.

Yoel Regev: I will add something about the nuclear family. It seems to me that a fundamental and basic contradiction of capitalism reveals itself here, about which Marx and Engels wrote long ago in the Manifesto, that, on the one hand, it is as though all is sacred, all connections and everything are substantially changed, but on the other, they are never changed to finality. An illusion is created that they may nevertheless be found somewhere and that they are necessary. Man is presented with the constant need to find this substantiality, to find these changed relations in a world in which they cannot be. And so the only means by which they can be found is the competitive society, where you can compare yourself against others. But this comparison is so structured-properly speaking, the very principle of comparison supposes - that this substantiality cannot be final. As soon as man defines himself in relations with another, this relationship is subject to the risk of revision and later on-an endless system of references.

In the sense, it seems to me that the nuclear family-and not just the nuclear family, but any relations at all-fulfils the function of such an illusory single anchor of salvation from the destructive connections of the market. But in actuality, this anchor of salvation is a necessary feature built into this very system. The very system supposes destruction, but never to completion. Nuclearity serves precisely this function, as do any other relations inside the capitalist model. 
Audience member: Do you think love is possible without relations of power?

Yelena Kostyleva: It seems not.

Audience member (continued): But why?

Yelena Kostyleva: The question and commentary have coincided. Powerlessness prompted no popular enthusiasm-nobody wanted to discuss powerlessness. Each of us, in one way or another, tries to say as few personal things as possible, but this isn't always successful. Powerlessness, love without relations of power, as it seems to me, might signify only their blocking and nothing more. Galya, might you put it more exactly? Is powerlessness provoked by prohibition or are you thinking of some other kind of powerlessness?

Galina Rymbu: It seems that the powerlessness of which I speak is actually binary. Or else there are two fundamentally different powerlessnesses. The first is social, economic, political and historical, structured by the coercive logic of surplus and deficit. It cannot find the means to escape the entrenched situation (of capitalism). It is the banal powerlessness in love, in which we all find ourselves-whether bourgeois or not, whether we sit in the center of Petersburg or on the outskirts of some provincial town. It is even, rather, desperation. It is not revolutionary nor is it counterrevolutionary. It is dependence, living a wretched existence in desperation, giving rise to such a huge force as the "love" affect, which people are incapable of withstanding. I am both against the understanding of monogamy and polygamy as counterrevolutionary and the demarcation between these two camps, as this only downplays a deeper problem. Both this and that form of the dictatorship of desire are powerless, i.e., hopeless. As are, alas, any collective regulatory projects of love.

The second powerlessness is one qualitatively different, insofar as it generally rejects the logic of force and resolution in love. Prohibition and permission exist in a regulatory structure: there, where force reigns, you cannot get by without prohibition, compromise, transgression etc. (in this sense, BDSM, incidentally, is a great liberating parody on such "desperateregulatory" love). It is important here to clarify this qualitatively powerless universal nature of love (not to create from scratch some kind of new phantom, but precisely to clarify, for the revolutionary embryo is already present in this complex of feelings and relations): without finitude (or infinity), without projectivity, without militancy or militarism, as even many leftist philosophers permit themselves to understand love as a war.

Olga (Tsaplya) Yegorova: What you say seems terribly beautiful to me, but utterly contradicts my own experience. First of all, you say that poly- 


\section{Discussion}

amory arises from surplus. It seems to me the reverse is true-from deficiency. I haven't got enough because I need more, right? Secondly, it seems to me that love gives a kind of strength. It always has done with me. Perhaps it's different for you. And so I am somewhat dumbfounded to take all this in. It seems to me that this is why people do not share and cannot understand your idea. Where is this weakness? Why do we want to surrender? In fact, we don't surrender-we give and take. It's such a cunning thing, love. It's a very powerful exchange.

Yoel Regev: There's some kind of equivocation here. The indistinguishability of two kinds of powerlessness. One is found with the person who is powerless in this situation, and the other powerlessness is created when the spring snaps and we go beyond the boundaries of this tension. But this is a kind of blackmail on behalf of the spring, which convinces us that we are now in a state of powerlessness and if I snap, there will be nothing left at all. It seems necessary to me that a means be found of distinguishing one powerlessness from the other. And to perceive and contemplate the second powerlessness in rather a different manner. Not as "without" something, but as...

Yelena Kostyleva: As a kind of transcendence, for example. There are transcendent states in love. They are absolutely powerlessness, absolutely non-projective and don't have to lead to anything, and there is nothing wrong with this at all... They have no temporality to them.

Olga (Tsaplya) Yegorova: Actually, apart from loving each other, it's also possible to love something. Something outside you. Then these agonies and powerlessness are structured a little and all these finitudes and infinities are somehow harmonized.

Yoel Regev: I fully agree, and think that what is needed is precisely a commune of researchers. But the problem lies in the fact that, in the current conditions, on the one hand there is a collective and that which unites it-affective sexual ties-and, on the other, there is whatever it is that they do. And these are two different things. It seems to me that the condition for the success of this commune will involve the elimination of this ambivalence. That such a commune might really exist, the relationships binding them need to be born from their activity. That is, to eliminate this ambivalence.

Olga (Tsaplya) Yegorova: Too little, too little...

Yelena Kostyleva: A typical critique from the left.

Dmitry Vilensky: I repeat that Brecht's theme of the third matter, the common cause, is vital. It seems that we are entangled in a rather abstract 
dispute, conditionally speaking, between productive and anti-productive lines. But after all, we are producing new institutions, new relations, new works, new world conditions. Properly speaking, both tendencies are present in leftist emancipatory discourse. Now, I would say, the "anti-" tendency prevails rather, and is dominant. Although, it seems, the accelerationists have another agenda-but this isn't productive either.

Artyom correctly noted that the "third matter" always turns out to be children for "normal" people-so you may see yourself beyond the boundaries of your finitude. And among people more given to worry about such themes, this can be art, revolution, philosophy, and so on. As Olga rightly said, from this dyad there may grow a far greater number of combinations, but they are always set in motion by some general energy of some undertaking.

Yoel Regev: I consider a child to be in some sense a move in the right direction, because a child is an eternal monument to the sexual act as a result of which he was produced. But I think that this movement must be continued and widened, until love is transformed into an eternal monument of itself.

Yelena Kostyleva: Firstly, thank you (Dmitry and Olga) for your well consolidated contribution, because this matter of the "third cause" is definitely worth thinking about. I recall, however, how polyamorists celebrate 14 February. It's comical, just imagine. There are five people. One says: "I wouldn't mind going to the pictures"; another answers him: "You what, that's so bourgeois it's insupportable!"; the third says: "Sorry, I'm reading a book-I'm not even here"; the fourth goes: "I'm sitting at home with the child today-I'm going nowhere." And the fifth, for example, is a legless hard-of-hearing queer, who didn't even understand the question.

What is the difference here between a traditional leftist commune and a possible polyamorous structure? The fact that, in polyamory, all subjects are consciously different-they might not even have any common activity. There are things that you shouldn't do together: you can't write poetry with four hands.

Artemy Magun: First of all, you can write poetry with four hands.

Secondly, there is love outside of a shared activity, but we are speaking now of the institutional restructuring of society. Of course, all these institutions must have something material on which they are based, and not just, forgive me, on affect. On affect you can't build anything at all. You can only build on a symbol. But a symbol must rely on some kind of interaction with the external world. And so I agree with Dima, that it is necessary to create libidinal corporations, which will deal with various vital issues. At the same time, in distinction from present-day corporations, they will be forged together on libidinal, but not amorphous, connections. 


\section{Discussion}

Olga (Tsaplya) Yegorova: I think it's even possible to have no common activity. But it is important to have common values, however.

Yelena Kostyleva: There are shared values here. You probably just missed them at the beginning. Polyamory is regarded as a new ethical system, a new ethic of relationships. There are such things in it as openness and honesty, and all gender theory and the entirety of feminism are brought into it, because this is a non-repressive system that must be built in such a way as to be inclusive, not excluding anybody. That is, people there "faff around" on the theme of-as Galya says-"how to love."

Artemy Magun: But we, by the way, didn’t understand it like that...

Oxana Timofeeva: If we suppose that everything is organised on the principle of comradely polyamorous communes, what is to be done with the inertia of the subject who doesn't wish to join the commune, but wants to be with a specific given comrade, and exclude the others?

Alexander Pogrebnyak: Oxana, Fourier has described this in detail. From onanism to the most polyamorous practices on the scale of the entire Phalanstery-please! Every evening is riddled with hundreds of intrigues, somebody will be in a couple tomorrow, somebody else in a foursome, another won't be with anyone at all-and will go clearing up litter to his heart's content.

The question is something else: in what way is Fourier an idealist? It seems to me that in his concept material plays into the hands of structure. And if the material doesn't play along? This is a question for Yoel too, by the way. Ontology can be idealistic, and it can be materialistic. The latter occurs when the material given has some deficiency and this deficiency, in a certain sense, problematizes any shortage. And then, instead of solutions we have the multiplication of problems that suggests no solutions. Why did Marx love him so-he said Fourier was better than Proudhon, or any other "fucker" besides-while rejecting almost 90 percent of Fourier's agenda to leave only the organization of the economy? Because Fourier's entire concept relies on the fact that material-passive Aristotelian material-fits our form totally. But this is idealism indeed!

Nikolai Kofyrin: Paraphrasing the author: does it not seem to you that nature is nevertheless stronger than culture, and that people live by instinct rather than by reason?

Yoel Regev: Such kind of argumentation very easily "careens off” into a thesis that is rightist by its nature. I would answer like this. It seems to me that not just the materialist, but also the materialist dialectic position is linked with the affirmation of two theses. The first thesis originates 
from the disobedience of material to us. It confirms that everything we can think of, everything that we do, our thought and our practice, are defined by nonplastic and external circumstances. Properly speaking, material is also that which defines thought. But the second thesis is no less important: despite the above shown fact, we have access to knowledge as to how this determinative external can be subjected to manipulation. We have knowledge about this. Otherwise it really would all be just idealism.

We have the technical wherewithal, we have the method. The importance of sexuality lies in the fact that it is also that sphere to which we have access-in the most privileged form-just as we have to this externality which determines our thought and actions. This is that very sphere in which we have access to the methodology that would allow us to exert and influence on and transform the external. That which Pepperstein refers to as "frobnication." Such "frobnication" has a sexual character.

Alexander Pogrebnyak: I fully agree here with the thesis of powerlessness. You are right that the point of radical chance is very important. And, properly speaking, sexuality is indeed an absolutely fetishistic thing too. In this sense, if we look at sexuality without the bullshit which it's so hung up on and which it will never cast off-and it will never concede its fetish, never sacrifice it-we also fall into idealism. The determining principle of sexuality is precisely this fetish that gives it its power, but which, precisely because of this, rends us powerless. Because, as soon as you let this fetish slip away, all your power goes up in smoke.

Yoel Regev: On the other hand, psychoanalysis. All psychoanalytical knowledge is founded upon the proposition that this sphere of investments can be manipulated, that certain translocation can be effected in this sphere, certain redistributions.

Anatoly: If we look at man as an imaginary being, that is, a determined imaginary, in the Lacanian sense, then it must be supposed that such delicate materials as love are cultivated there and find there their energy. To the question on how capitalism expresses its reactionary essence: most likely, it occupies and colonizes this imaginary with incursions of the symbolic. How to live with this, with all this love, in communes-and what use are they anyway? People are not even inclined to go out at all-this is already a contemporary statistic. They get everything while sitting at their computers and don't need a thing.

Artemy Magun: The great poet of the society you have described, Viktor Pelevin, says in this vein that the most important thing in a womanthere are two important things really, but I'll forego mention of the second. The first of them is a hypnotableau [a reference to the futuristic technology in Pelevin's "Snuff” novel-translator]. This is a metaphor. It boils 


\section{Discussion}

down to woman being a walking television. But man, too. In actual fact, nothing changes-we all live in a world of daydreams. And it is from this that we began. And our task here with our colleagues is to set up some kind of barrier blocks in it for the user.

Oleg: There is one simple obvious thing-the collective doesn't have sex. The individual has sex. And, in creating a commune, you don't guarantee the emergence of a new sexuality at all-it may just reproduce the previous kind. By way of contrast, when some new Marquis de Sade comes along with a new understanding of love, then a new sexuality will appear.

Yelena Kostyleva: In this sense, I would like to get something straight: we aren't setting up any kind of commune yet at all.

Artemy Magun: As a summary of the discussion-Y. Kostyleva has reconsidered.

Yelena Kostyleva: People always confuse the commune, community, and polyamory. In polyamory, there is another subject, comrades. The subject of polyamory is the relationships themselves. And so this kind of sexuality is something new. In any case, historically, there has not yet been seen anything that has described itself in any similar fashion.

Artemy Magun: Thank you! And here, on these words of Yelena, we draw our discussion to a close. 